\title{
DAMPAK PEMBANGUNAN BANDARA HALU OLEO TERHADAP PERUBAHAN KESEJAHTERAAN MASYARAKAT DI DESA AMBAIPUA KECAMATAN RANOMEETO KABUPATEN KONAWE SELATAN
}

\author{
Sulkifli Ananda Dewantara', Syaifuddin S. Kasim², Sarmadan ${ }^{3}$ \\ ${ }^{123}$ Fakultas Ilmu Sosial dan Ilmu Politik Universitas Halu Oleo \\ E-mail: Sulkifliananda1@gmail.com, syaifuddinkasimsos@gmail.com, Sarmadanhamid1972@gmail.com \\ Korespondensi: Sarmadan
}

do

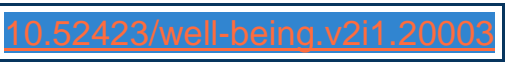

ABSTRACT

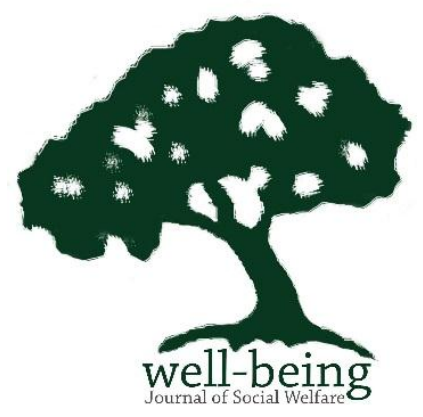

\begin{abstract}
This study aims to determine the impact of airport construction on socio-economic and territorial changes in the community in Ambaipua village, Ranomeeto sub-district, South Konawe district. This type of research is descriptive qualitative, one type of research whose aim is to present a complete picture of the social setting or is intended for exploration and clarification of a phenomenon or social reality, by describing those with regard to the problem and the unit under study between the phenomena being tested. Meanwhile, the informants in this study are the people of Ambaipua Village who work at Halu Oleo Airport and the people of Ambaipua Village around Halu Oleo Airport. The results showed that: 1) Social impact: Increased population mobility, Improvement of community social networks, Social Interaction. 2) Economic Impact: Increase in negotiations and trade agreements, Shipping of trade goods. 3) Territorial Impact: Creating new jobs for the community, Increasing community income, Creating healthy price stability.
\end{abstract}

Keywords: Development Impact, Socio-Economic Change

\section{PENDAHULUAN}

Bandar Udara Halu Oleo (sebelumnya Bandar Udara Wolter Monginsidi) adalah bandar udara di Kabupaten Konawe Selatan, Sulawesi Tenggara, Indonesia. Sebelumnya nama bandar udara ini diambil dari nama Robert Wolter Monginsidi, pahlawan nasional Indonesia yang dieksekusi oleh Belanda selama Revolusi Nasional Indonesia. Sejak 13 Februari 2010, nama bandar udara ini diubah untuk menghormati raja Konawe, yakni Raja Halu Oleo. Bandara Haluoleo adalah UPBU Kelas I dan merupakan enclave sipil yang berada di Kabupaten Konawe Selatan, Provinsi Sulawesi Tenggara. Bandara Haluoleo telah mengalami beberapa peningkatan pelayanan, khususnya dengan adanya fasilitas Aerobridge atau Garbarata yang memudahkan penumpang memasuki kawasan terminal keberangkatan dan kedatangan bandara dan menuju dari dan ke pesawat udara. Pembangunan bandara Haluoleo tidak bisa dipungkiri juga akan menciptakan perubahan yang signifikan terhadap masyarakat termasuk perubahan di bidang sosial dan ekonomi masyarakat. Perubahan sosial ekonomi yang terjadi pada masyarakat merupakan perubahan terkait segala sesuatu yang berkaitan dengan pemenuhan kebutuhan masyarakat antara lain sandang pangan, perumahan, pendidikan dan kesehatan, yang mana pemenuhan kebutuhan ini erat kaitannya dengan penghasilan. Perubahan ini terjadi karena perubahan lingkungan tempat tinggal masyarakat, yang secara langsung berdampak pula terhadap sosial dan ekonomi masyarakat. Perubahan ini dapat berupa tingkah laku masyarakat yang dahulu kental dengan kekerabatan khas masyarakat desa tentu akan terpengaruhi dengan munculnya bandara ini yang akan 
mendorong masyarakat menuju lebih modern dengan interaksi sosial yang intensitas tentu lebih berkurang dibanding sebelum munculnya pembangunan bandara. Dampak secara ekonomi juga mempengaruhi masyarakat dengan hadirnya Bandara Halu Oleo, hal ini dikarenakan pihak bandara Haluo Oleo membuka lapangan pekerjaan bagi pemuda-pemudi lulusan sekolah menengah atas dan lulusan sarjana yang tinggal di sekitar bandara Halu Oleo dan tidak mempunyai pekerjaan. Hal ini tentu akan membuat perubahan pada ekonomi masyarakat.

Menurut Wamenhub dan Pemerintah Pusat khususnya di Sulawesi Tenggara Bandara Halu Oleo, memiliki komitmen yang kuat untuk mendukung upaya pemerintah daerah dalam membangun dan mengembangkan sistem transportasi efektif dan efisien tersebut. Karenanya, setiap tahun pemerintah selalu menganggarkan alokasi pendanaan dalam mata Anggaran Pendapatan dan Belanja Negara (APBN), baik untuk pembangunan maupun pengembangan sarana dan infrastruktur transportasi di seluruh Indonesia. Melalui Peraturan Presiden Nomor 56 Tahun 2018 tentang Perubahan Peraturan Presiden Nomor 3 Tahun 2016 tentang Percepatan Pelaksanaan Proyek Strategis Nasional terkait pembangunan yang berlokasi di Kabuaten Konawe Selatan, Proyek pembangunan Bandara ini tentu akan menciptakan perubahan sosial ekonomi masyarakat yang terdampak pembangunan, perubahan-perubahan ini meliputi interaksi sosial antar masyarakat setelah adanya proses pembnagunan bandara, perubahan mata pencaharian masyarakat dan bentuk bentuk perubahan sosial lainnya yang terjadi di masyarakat, sehingga peneliti memfokuskan penelitian pada dampak perubahan sosial ekonomi masyarakat terdampak pembangunan Bandara Halu-Oleo.

\section{METODE PENELITIAN}

Penelitian ini dilakukan di Desa Ambaipua Kecamatan Ranomeeto Kabupaten Konawe mulai bulan FebruariJuni 2020. Jenis penelitian ini merupakan deskriptif kualitatif, yang mana peneliti berusaha mengkaji, menelaah dan juga dapat menguraikan data yang akan didapatkan dilapangan yakni mengenai Dampak Pembangunan Bandara Halu Oleo Terhadap Perubahan Kesejahteraan Masyarakat Di Desa Ambaipua Kecamatan Ranomeeto Kabupaten Konawe Selatan. Metodologi kualitatif sebagai prosedur penelitian yang menghasilkan data deskriptif berupa kata-kata tertulis atau lisan dari informan. Adapun informan dalam penelitian ini berjumlah 12 orang orang yang terdiri dari Security PT Global, Petugas senior PPK, Sopir kendaraan operasional, Supir rental Bandara, Jasa pelayanan Bandara, Pedagang buahbuahan yang berjumlah dua orang, Kepala Desa Ambaipua, Aviation security, Pedagang makanan diluar Bandara, Aviation Security, Pemilik butik. Jenis data yang dikumpulkan dalam penelitian ini adalah data kualitatif dan data kuantitatif. Sumber data yang dikumpulkan dalam penelitian ini adalah data primer dan data sekunder. Teknik pengumpulan data yang digunakan adalah Pengamatan (observasi), wawancara (interview), dan dokumentasi. Teknik analisis data dalam penelitian ini, peneliti menggunakan analisis data model Miles dan Hurberman (1992): yaitu: Pengumpulan Data (Data Collection), Reduksi data (Data Reduction), Penyajian data (Data Presentation), Penarikan kesimpulan (Conclusion Drawing). Adapun langkah-langkah yang peneliti gunakan adalah: Mengumpulkan atau merangkum data yang diperoleh dari proses wawancara dengan pihak untuk dianalisis, 
Menafsirkan data yang diperoleh, Menarik kesimpulan terhadap apa yang diteliti.

\section{HASIL DAN PEMBAHASAN Dampak Pembangunan Bandara Halu Oleo Terhadap Perubahan Kesejahteraan Masyarakat Di Desa Ambaipua Kecamatan Ranomeeto Kabupaten Konawe Selatan.}

\section{Sosial}

a) Bertambahnya mobilitas penduduk

Dapat disimpulkan bahwa dengan adanya Bandara Halu Oleo dapat membuat perpindahan penduduk dari suatu wilayah ke wilayah lain (mobilitas penduduk) menjadi bertambah khususnya pada masyarakat Desa Ambaipua Kabupaten Konawe Selatan dan masyarakat diluar provinsi Sulawesi Tenggara yang hendak datang ke Desa Ambaipua. Hal tersebut terjadi karena beberapa alasan seperti alasan pekerjaan, pendidikan, untuk datang tinggal menetap atau sementara dan karena alasan bencana alam . Selain itu,Salah satu tujuan Pembangunan Bandara Halu Oleo adalah agar dapat memudahkan masyarakat bepergian ke suatu wilayah tertentu di seluruh Indonesia maupun di luar negeri,sehingga bertambahnya mobilitas penduduk adalah hal yang pasti terjadi dengan adanya bandara pada masyarakat Desa Ambaipua.

b) Peningkatan terhadap jaringan social masyarakat

Pembangunan Bandara Halu Oleo berdampak pada peningkaan jaringan sosial masyarakat sekitar Bandara Halu Oleo yaitu masyarakat Desa Ambaipua. Jaringan sosial adalah sebuah pola hubungan sosial individu maupun kelompok dalam berbagai bentuk yang sifatnya kolektif. Adapun hubungan tersebut dapat bersifat hubungan interpersonal yang bersifat ekonomi, politik maupun hubungan sosial lainnya.
Masyarakat Desa Ambepua yang bekerja dan berdagang disekitaran Bandara Halu Oleo dapat bertemu dengan orang-orang yang berasal dari daerah lain maupun orang-orang dari Sulawesi Tenggara diluar dari Desa Ambaipua lalu kemudian mereka tersebut menggunakan jasa rental mobil,membeli buah-buahan, dan makanan sehingga lama-kelamaan terjalin hubungan interpersonal yang bersifat ekonomi yaitu sebagai pelanggan tetap masyarakat Desa Ambepua yang bekerja dan berdagang disekitran Bandara Halu Oleo. Selain itu, masyarakat Desa Ambaipua yang bekerja di Bandara Halu Oleo dapat menjalin hubungan baik dengan individu yang berasal dari luar Sulawesi Tenggara karena mereka selalu menolong dan membantu.

c) Interaksi sosial

Keberadaan Bandara Halu Oleo memungkinkan masyarakat Desa Ambaipua melakukan interaksi sosial melalui kontak sosial secara langsung dengan individu atau kelompok yang berada di sekitar Bandara Halu Oleo. dampak keberadaan bandara tersebut membut Interaksi sosial dapat terjadi karena banyak masyarakat Desa Ambaipua yang bekerja di Bandara Halu Oleo dan masyarakat Desa Ambaipua yang memanfaatkan keberadaan Bandara Halu Oleo untuk membuka usaha di sekitaran Bandara.

\section{Ekonomi}

a) Peningkatan negosiasi dan perjanjian perdangangan

Negosiasi dan perjanjian perdagangan merupakan sebuah bentuk interaksi sosial saat pihak-pihak yang terlibat berusaha untuk saling menyelesaikan tujuan dan mencapai suatu kesepakatan. Keberadaan Bandara Halu Oleo memungkinkan terjadinya negosiasi dan perjanjian perdagangan antar 
perdagangan antara masyarakat Desa Ambaipua dengan pedagang yang berada diluar daerah Sulawesi Tenggara, misalnya di Sulawesi Selatan, Jakarta, Bandung, dan lain-lain.
b) Pengiriman
Barang-barang

perdagangan

Pengiriman barang dagang merupakan salah satu penunjang berjalannya suatu usaha. Tanpa adanya pengiriman barang, usaha tersebut tidak akan berjalan karena akan terjadi kekosongan barang dagang. Dengan adanya Bandara Halu Oleo memungkinkan masyarakat Desa Ambaipua untuk membuka usaha dagang seperti berjualan baju, buah, dan lain-lain.

\section{Kewilayahan}

a) Terciptanya Lapangan Kerja baru bagi masyarakat

Lapangan pekerjaan merupakan suatu bidang mengenai kegiatan usaha ataupun perusahaan ataupun instansi yang bisa ditempati seseorang bekerja atau pernah ditempati bekerja danbisa juga diartikan sebagai ketersediaan kerja atau pekerjaan yang bisa diisi oleh tenaga kerja. Awal berdiri bandara halu oleo desa ambaipua penghasilan masyarakat setempat meningkat, beda sebelum bandara halu oleo ada karena memungkinkan masyarakat untuk membuat usaha.Selain itu banyak masyarakat yang awalnya bekerja ditempat lain dengan gaji yang tidak terlalu tinggi namun setelah bekerja di Bandara Halu Oleo gajinya menjadi meningkat.

b) Meningkatkan Pendapatan Masyarakat

Pendapatan masyarakat adalah jumlah penghasilan yang diterima oleh masyarakat atas prestasi kerjanya selama satu periode tertentu, baik harian, mingguan, bulanan ataupun tahunan. Dengan adanya Bandara Halu Oleo memungkinkan masyarakat Desa
Ambaipua untuk meningkatkan pendapatan mereka apa lagi bagi mereka yang berjualan/berdagang di sekitar bandara tersebut.

c) Mewujudkan Stabilitas Harga Yang Sehat

Stabilitas perekonomian menciptakan stabilitas harga karena perekonomian yang stabil mampu menyebabkan biaya yang rendah atau terjangkaunya bagi masyarakat. Sebaliknya, ketidakstabilan akan menyengsarakan masyarakat karena rencana masa depan sulit tercapai, khususnya dalam jangka panjang terkait investasi. Keberadaan Bandara Halu Oleo telah memberikan pengaruh terhadap semakin meningkatnya pembangunan-pembangunan yang terjadi disekitar kawasan Bandara. Kawasan tersebut pun semakin lama menjadi pusat perhatian para investor untuk melakukan pembangunan disekitar Bandara Halu Oleo. Seperti pembangunan minimarket dan supermarket yang karena hal tersebut dapat membuat harga stabil.

\section{KESIMPULAN}

Penelitian ini disesuaikan untuk mengetahui dampak pembangunan bandara terhadap perubahan Kesejahteraan dan kewilayahan masyarakat di Desa ambaipua Kecamatan Ranomeeto Kabupaten Konawe Selatan. Berdasarkan data yang terkumpul dan setelah dilakukan penelitian, maka dapat diambil kesimpulan sebagai berikut :

1. Dampak sosial keberadaan Bandara Halu Oleo terhadap masyarakat Desa Ambaipua Kecamatan Ranomeeto Kabupaten Konawe Selatan Adalah sebagai berikut:

a) Bertambahnya mobilitas penduduk

Mobiltas penduduk adalah perpindahan penduduk dari suatu 
daerah ke daerah yang lain. Mobilitas penduduk dapat dibedakan antara mobilitas penduduk vertikal dan mobilitas penduduk horizontal. Mobilitas penduduk vertikal sering disebut dengan perubahan status dan salah satu contohnya adalah perubahan status pekerjaan. Seorang yang mulamula bekerja dalam sektor pertanian sekarang bekerja dalam sektor non pertanian. Sedangkan mobilitas penduduk geografis adalah gerak penduduk yang melintasi batas wilayah menuju ke wialayah lainnya dalam periode waku tertentu. Pembangunan Bandara Halu Oleo Kendari telah memberikan dampak sosial bagi masyarakat salah satunya yaitu mobilitas penduduk geografis. Hal ini terjadi karena bandara merupakan wadah atau tempat yang menyediakan transportasi udara bagi para penumpang yang bepergian disuatu wilayah tertentu.

Dengan adanya Bandara Halu Oleo dapat membuat perpindahan penduduk dari suatu wilayah ke wilayah lain (mobilitas penduduk) menjadi bertambah khususnya pada masyarakat Desa Ambaipua Kabupaten Konawe Selatan dan masyarakat diluar provinsi Sulawesi Tenggara yang hendak datang ke Desa Ambaipua. Hal tersebut terjadi karena beberapa alasan seperti alasan pekerjaan, pendidikan, untuk datang tinggal menetap atau sementara dan karena alasan bencana alam . Selain itu, Salah satu tujuan Pembangunan Bandara Halu Oleo adalah agar dapat memudahkan masyarakat bepergian ke suatu wilayah tertentu di seluruh Indonesia maupun di luar negeri,sehingga bertambahnya mobilitas penduduk adalah hal yang pasti terjadi dengan adanya bandara pada masyarakat Desa Ambaipua. b) Peningkatan Terhadap jaringan sosial masyarakat.

Pembangunan Bandara Halu Oleo berdampak pada peningkaan jaringan sosial masyarakat sekitar Bandara Halu Oleo yaitu masyarakat Desa Ambaipua. Jaringan sosial adalah sebuah pola hubungan sosial individu maupun kelompok dalam berbagai bentuk yang sifatnya kolektif. Adapun hubungan tersebut dapat bersifat hubungan interpersonal yang bersifat ekonomi, politik maupun hubungan sosial lainnya.

Adanya Bandara Halu Oleo membuat masyarakat Desa Ambaipua yang bekerja dan berdagang disekiran Bandara Halu Oleo dapat menjalin hubungan interpersonal dengan kelompok atau individu yang berasal dari dari dalam dan luar Sulawesi Tenggara yang bersifat ekonomi dan hubungan sosial lainnya. Hal ini terjadi karena masyarakat Desa Ambepua yang bekerja dan berdagang disekitran Bandara Halu Oleo dapat bertemu dengan orang-orang yang berasal dari daerah lain maupun orang-orang dari Sulawesi Tenggara diluar dari Desa Ambaipua lalu kemudian mereka tersebut menggunakan jasa rental mobil,membeli buah-buahan, dan makanan sehingga lama-kelamaan terjalin hubungan interpersonal yang bersifat ekonomi yaitu sebagai pelanggan tetap masyarakat Desa Ambepua yang bekerja dan berdagang disekitran Bandara Halu Oleo. Selain itu, masyarakat Desa Ambaipua yang bekerja di Bandara Halu Oleo dapat menjalin hubungan baik dengan individu yang berasal dari luar Sulawesi Tenggara karena mereka selalu menolong dan membantu.

c) Interaksi Sosial

Interaksi sosial adalah hubungan timbal balik antara individu dengan 
individu maupun kelompok, atau kelompok dengan kelompok.Syarat terjadinya interaksi sosial yaitu adanya kontak sosial baik itu secara langsung atau tidak langsung. Keberadaan Bandara Halu Oleo memungkinkan masyarakat Desa Ambaipua melakukan interaksi sosial melalui kontak sosial secara langsung dengan individu atau kelompok yang berada di sekitar Bandara Halu Oleo.

Dampak pembangunan Bandara Halu Oleo membuat masyarakat Desa Ambaipua dapat berinteraksi dengan banyak orang terutama orang-orang yang hendak bepergian keluar daerah atau orang-orang yang datang ke Sulawesi Tenggara melalui Bandara Halu Oleo. Interaksi sosial tersebut dapat terjadi karena banyak masyarakat Desa Ambaipua yang bekerja di Bandara Halu Oleo dan masyarakat Desa Ambaipua yang memanfaatkan keberadaan Bandara Halu Oleo untuk membuka usaha di sekitaran Bandara.

2. Dampak Ekonomi Keberadaan Bandara Halu Oleo terhadap masyarakat Desa Ambaipua Kecamatan Ranomeeto Kabupaten Konawe Selatan Adalah sebagai berikut:

a) Peningkatan negosiasi dan perjanjian perdagangan.

Negosiasi dan perjanjian perdangangan merupakan sebuah bentuk interaksi sosial saat pihakpihak yang terlibat berusaha untuk saling menyelesaikan tujuan dan mencapai suatu kesepakatan. Keberadaan Bandara Halu Oleo memungkinkan terjadinya negosiasi dan perjanjian perdagangan antar perdagangan antara masyarakat Desa Ambaipua dengan pedagang yang berada diluar daerah Sulawesi Tenggara, misalnya di Sulawesi
Selatan, Jakarta, Bandung, dan lainlain.

Dengan keberadaan Bandara Halu Oleo membuat masyarakat Desa Ambaipua khususnya penjual buahbuahan, merasa terbantu dengan adanya Bandara Halu Oleo yang di mana pengiriman bibit lebih cepat sehingga kualitas bibit yang datang lebih bagus, dan juga proses neosiasi antara penjual buah di desa ambaipua dan penjual bibit sangat lancar tanpa hambatan sehingga proses negosiasi sangat lancar.Begitupun dengan pemilik butik yang merasa sangat terbantu dalam menjalankan bisnisnya karena adanya Bandara Halu Oleo yang memungkinkan untuk dapat membeli kain dari luar sulawesi Tenggara.

b) Pengiriman barang-barang perdagangan.

Pengiriman barang dagang merupakan salah satu penunjang berjalannya suatu usaha. Tanpa adanya pengiriman barang, usaha tersebut tidak akan berjalan karena akan terjadi kekosongan barang dagang. Dengan adanya Bandara Halu Oleo memungkinkan masyarakat Desa Ambaipua untuk membuka usaha dagang seperti berjualan baju, buah, dan lain-lain.

Ibu Dwi selaku pengusaha butik sangat terbantu dengan adanya bandara. Yang dimana pengiriman barang dagang menjadi lebih lancar dan perjanjian kontrak dapat di lakukan oleh Ibu Dwi dan toko pemesanan baju. Perjanjian perdagangan juga menjadi perjanjian jangka panjang sehingga Ibu Dwi tidak perlu lagi mencari toko lain, dan toko tersebut juga tidak perlu mencari tempat lain untuk mengirim barang dagangan. Selain itu bapak Tito juga dapat lebih muda untuk menjalankan 
bisnis sampingannya yaitu menjual baju karena dia bisa memanfaatkan Bandara Halu Oleo untuk dapat menerima kiriman barang dalam hal ini pakaian dari luar Sulawesi Tenggara.

3. Dampak Kewilayahan Keberadaan Bandara Halu Oleo terhadap masyarakat Desa Ambaipua Kecamatan Ranomeeto Kabupaten Konawe Selatan Adalah sebagai berikut:

a) Terciptanya lapangan pekerjaan baru bagi masyarakat.

Lapangan pekerjaan merupakan suatu bidang mengenai kegiatan usaha ataupun perusahaan ataupun instansi yang bisa ditempati seseorang bekerja atau pernah ditempati bekerja dan bisa juga diartikan sebagai ketersediaan kerja atau pekerjaan yang bisa diisi oleh tenaga kerja.Dengan adanya Bandara Halu Oleo memungkinkan masyarakat Desa Ambaipua untuk mendapatkan pekerjaan agar mengurangi peningkatan pengangguran di desa ambaipua.

Setiap tahun di adakan penerimaan karyawan dan tetap memprioritaskan masyarakat ambaipua untuk menjadi karyawan di bandara halu oleo. Seperti saudara fahrul yang sejak tahun 2016 telah menjadi karyawan di bandara halu oleo dan mayoritas masyarakat desa ambaipua diterima di Bandara Halu Oleo.

b) Meningkatkan pendapatan masyarakat.

Pendapatan masyarakat adalah jumlah penghasilan yang diterima oleh masyarakat atas prestasi kerjanya selama satu periode tertentu, baik harian, mingguan, bulanan ataupun tahunan. Dengan adanya Bandara Halu Oleo memungkinkan masyarakat Desa Ambaipua untuk meningkatkan pendapatan mereka apa lagi bagi mereka yang berjualan/berdagang di sekitar bandara tersebut.

Awal berdiri bandara halu oleo desa ambaipua penghasilan masyarakat setempat meningkat, beda sebelum bandara halu oleo ada karena memungkinkan masyarakat untuk membuat usaha.Selain itu banyak masyarakat yang awalnya bekerja ditempat lain dengan gaji yang tidak terlalu tinggi namun setelah bekerja di Bandara Halu Oleo gajinya menjadi meningkat.

c) Mewujudkan stabilitas harga yang sehat.

Stabilitas

perekonomian menciptakan stabilitas harga karena perekonomian yang stabil mampu menyebabkan biaya yang rendah atau terjangkaunya bagi masyarakat. Sebaliknya, ketidakstabilan akan menyengsarakan masyarakat karena rencana masa depan sulit tercapai, khususnya dalam jangka panjang terkait investasi.Keberadaan Bandara Halu Oleo telah memberikan pengaruh terhadap semakin meningkatnya pembangunan-pembangunan yang terjadi disekitar kawasan Bandara. Kawasan tersebut pun semakin lama menjadi pusat perhatian para investor untuk melakukan pembangunan disekitar Bandara Halu Oleo. Seperti pembangunan minimarket dan supermarket yang karena hal tersebut dapat membuat harga stabil.

Seperti yang dilakukan oleh masyarakat Desa Ambaipua yang berjualan dan bekerja disekitaran Bandara yaitu ibu ati menjual dan berbelanja di toko dengan mengambil barang grosiran sehingga mendapat harga yang worth it. Dan adapun tambahan dari saudara bobi, pada saat berbelanja di warung dia mendapatkan harga yang sesuai atau harga yang murah meriah. 


\section{DAFTAR PUSTAKA}

Abbas, Salim. 2000. Manajemen Transportasi. Cetakan Pertama. Edisi Kedua. Jakarta : Ghalia Indonesia.

Adisasmita, Rahardjo. 2010. Pembangunan Kawasan dan Tata Ruang. Yogyakarta : Graha Ilmu.

B.F. Hoselitz, 1988, Panduan Dasar IlmuIlmu Sosial, Jakarta: Rajawali Press.

Esmara. 1986. Sumber Daya Manusia, Kesempatan Kerja Dan Perkembangan Ekonomi. UI Press. Jakarta.

Fakih, Mansour. 2013. Runtuhnya Teori Pembangunan dan Globalisasi. Yogyakarta: INSIST Press \& Pustaka Pelajar.

Sztompka, Piotr. 2008. Sosiologi Perubahan Sosial. Jakarta: Prenada Media Group. Hal. 21

Todaro, Michael P \& Burhanuddin. 1987. Pembangunan Ekonomi Di Dunia Ketiga. Jakarta: Erlangga.

Wolcott, Richard C. 1987. The Appraisal of Real Estate American Institute of Real Estate Appraiser. North Michigan, Chicago Illinois. 